\title{
Cloud Computing for Natural Disasters and Emergency Response Simulation Games
}

\author{
Rafael P. Saldaña \\ Ateneo de Manila University \\ Loyola Heights, Quezon City 1108, Philippines \\ E-mail: rsaldanalateneo.edu
}

The Philippines is one of the most hazard-prone countries in the world. This is due mainly to its geographic and geologic location and physical characteristics. The country is situated in the "Pacific Ring of Fire", between two tectonic plates (Eurasian and Pacific), an area encircling the Pacific Ocean where frequent earthquakes and volcanic activity result from the movements of said tectonic plates. Recent statistics show that worldwide the Philippines has one of the highest number of people affected by natural disasters and has one of the highest disaster risk index. The country is exposed to a variety of hazards such as floods, earthquakes, typhoons, storm surges, tsunamis, volcanic eruptions, landslides, droughts, etc.

To increase awareness on tsunamis and other natural hazards in the Philippines and to promote disaster preparedness, risk reduction and management we conducted a study among young people in the country using computer simulation games developed by the United Nations/International Strategy for Disaster Risk Reduction. Called “Stop Disasters!" , this online game features five natural hazards: (1) tsunami, (2) hurricane, (3) wildfire, (4) earthquake, and (5) flood. The subjects of this study are mainly teen-agers from public and private high schools, college level students from public and private universities, and young professionals. The study assessed the benefits of using computer simulation games in disaster risk reduction and the Filipino youth's perception on the disaster simulation game, "Stop Disasters!"

After each game, the respondents were asked the following questions: (1) Do you think that computer simulation games can be beneficial in disaster preparedness, risk reduction and management? (2) What do like best in the game "Stop Disasters!"? (3) What don't you like in the game "Stop Disasters!"? (4) Would you recommend the game "Stop Disasters!" to your friends or relatives? Why or Why not? (5) Did the game "Stop Disasters!" increase your understanding of disaster preparedness, risk reduction and management? (6) Give suggestions/recommendations on how to improve the game "Stop Disasters!". Results of the study show that young people find the use of computer simulation games such as "Stop Disasters!" beneficial in improving their understanding of disaster preparedness, risk reduction and management. Recommendations on how to improve the simulation game "Stop Disasters!" to suit local situations/conditions in the Philippines are given. Cloud computing as a tool for disaster simulation games is also explored.

International Symposium on Grids and Clouds (ISGC) 2015

15 -20 March 2015,

Academia Sinica, Taipei, Taiwan 


\section{Introduction}

Every year many natural disasters happen all over the world: earthquakes, tsunamis, tropical storms (cyclones), and floods are some of the most devastating disasters. Recently, simulation games have been used in disaster preparedness and risk reduction training programs, specially for young people.

In this paper, we present some disaster simulation games and initiatives applied in different countries. Among these games are "Stop Disasters!", "Disaster Master", "Storm Watchers", and Cloud-based Earthquake Simulation Games Competition.

\section{0 “Stop Disasters!” Study in Brazil}

Felicio and co-workers [3] studied a group of children aged 10 to 13 years old selected at random from a high school in Rio de Janairo, Brazil. They used the "Stop Disasters!" online simulation game developed by the United Nations Insternational Strategy for Disaster Reduction (UNISDR) [9]. This game features five natural hazards: (1) tsunami, (2) hurricane, (3) wildfire, (4) earthquake, and (5) flood.

At the beginning of the study, the students were asked to choose one of five natural hazards: a tsunami, a hurricane, a wildfire hitting arid plains, an earthquake hitting lowland hills or a flood hitting a valley town. However, during the application of the game Felicio and coworkers focused only on the flood scenario, since that kind of disaster is "virtually the only one faced by the Brazil population" [3].

Based on the results of their study, Felicio and co-workers concluded that the game "Stop Disasters!" raised awareness of natural diasters such as flooding, faced by the population of Rio de Janeiro, Brazil [3].

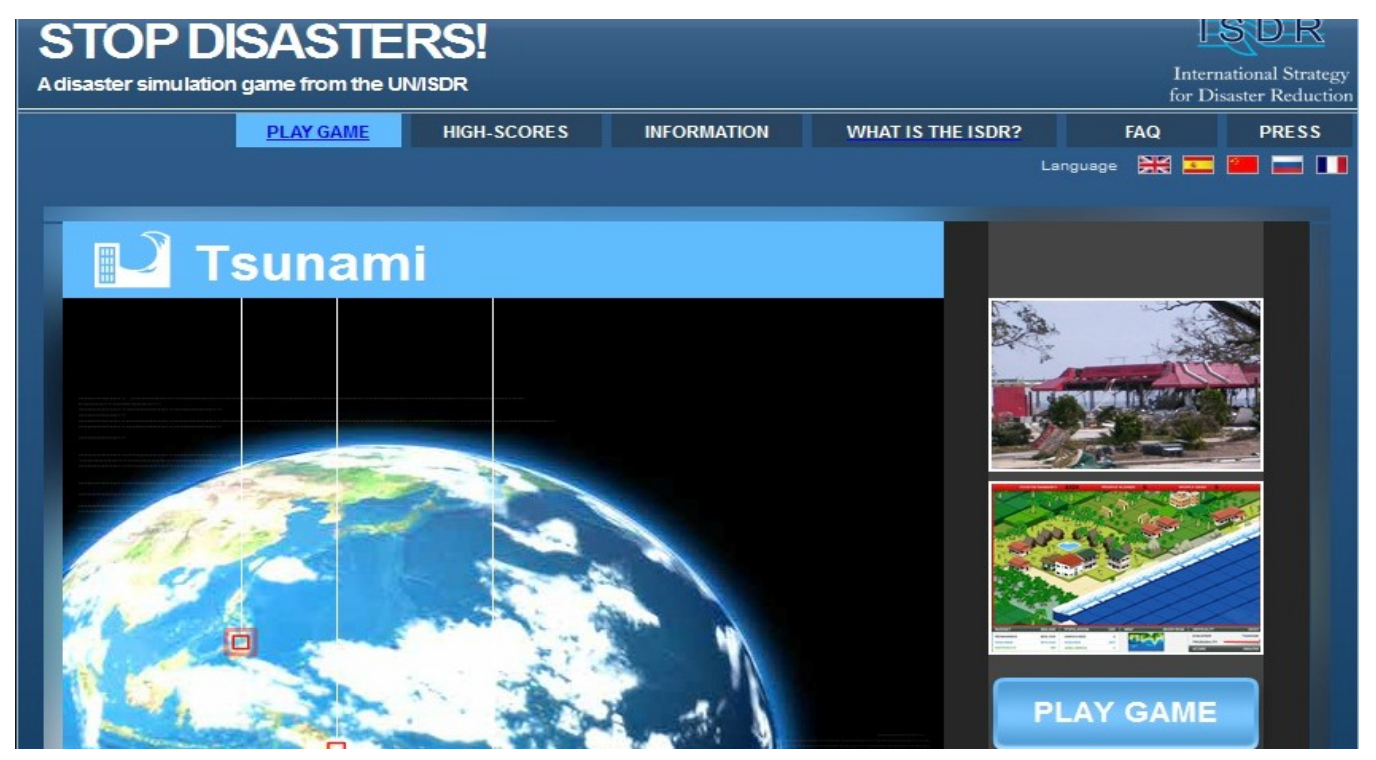

Figure 1: A Screenshot of "Stop Disasters!” Game [9] 


\section{0 "Disaster Master"}

"At the Department of Homeland Security's Ready.gov website, kids can play an online game called Disaster Master in which they help a diverse group of cartoon heroes cope with seven different types of mayhem: wildfire, tornado, hurricane/blackout, home fire, winter storm/extreme cold, tsunami/earthquake and thunderstorm/lightning. Four levels are available for children at different grade levels: early and late elementary, middle school and high school. A downloadable project-based curriculum offers three aligned lessons."[2]

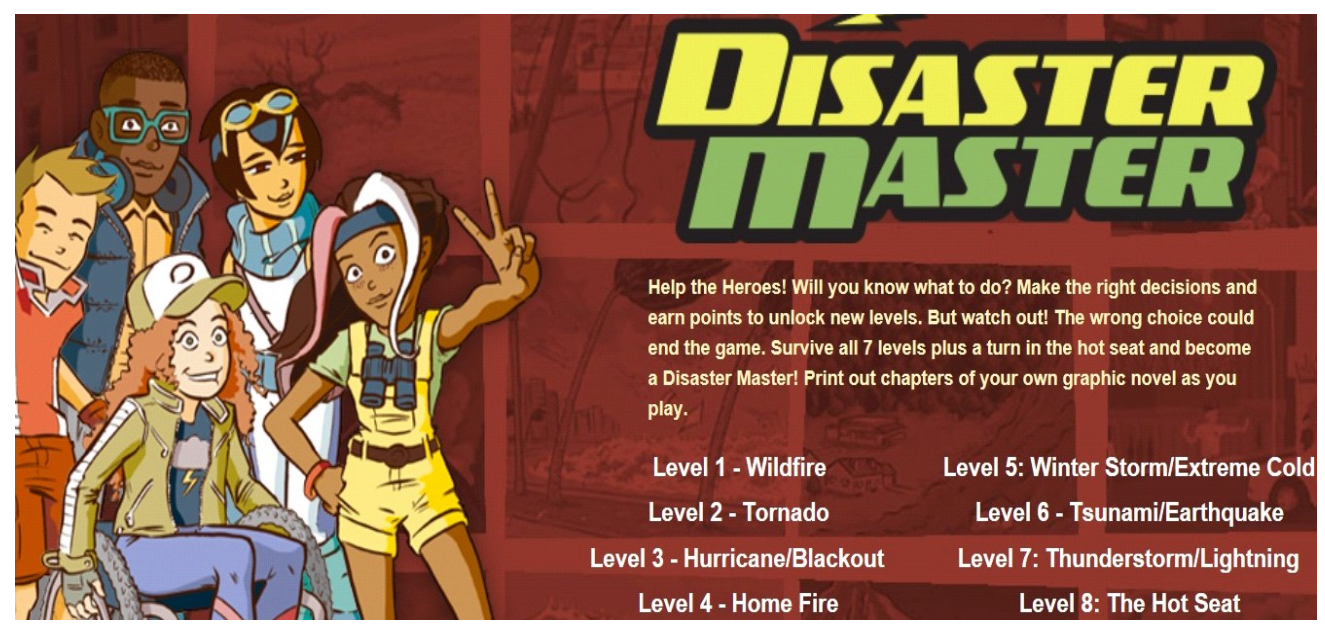

Figure 3: A Screenshot of the 'Disaster Master' Game [4]

\section{0 "Storm Watchers" in Australia}

In Australia, "the Tropical Cyclone Coastal Impacts Program (TCCIP) in the early 1990's showed that there was a need for an age appropriate tropical cyclone awareness educational package to assist children in their understanding of the risks associated with tropical cyclones. In response to the research from the TCCIP the Centre for Disaster Studies in conjunction with the Bureau of Meteorology developed 'Stormwatchers' an interactive cyclone awareness game for children. The game was first developed as an interactive CD ROM package that was distributed throughout Queensland schools and was later modified for Western Australia. Throughout the late 90 's the game was seen as an important educational tool for cyclone awareness and preparedness across Queensland." [1]

"The new version of Stormwatchers is a 3D interactive web based game. It has been expanded from the original to include the psychological effects of tropical cyclones to children and tools that allow children to create an emergency action plan for their house. There are links in the game to all state agencies responsible for emergency management across tropical Australia to ensure children and their families have access to the most up to-date information available." [1]

"The game is designed to be practical and appropriate for children across tropical Australia. The game allows children to choose the state in which they live to create their own cyclone experience by working through one of 5 'true-to-life' cyclone scenarios with one of the game's characters. The game provides children with the skills to enable them to be better prepared in a real cyclone situation." [1] 
"Along the way they learn how to help prepare their home for a tropical cyclone, interpret cyclone warning systems while they track and plot the approach of a tropical cyclone in their region. They will ascertain and purchase emergency kit supplies, prepare a family emergency plan and identify a safe place to shelter with information provided that is specific to each states emergency procedures. The game is aimed at children in the 7 to 13 -year-old bracket but there is information presented in the quiz and fact book that will be informative for the whole family." [1]

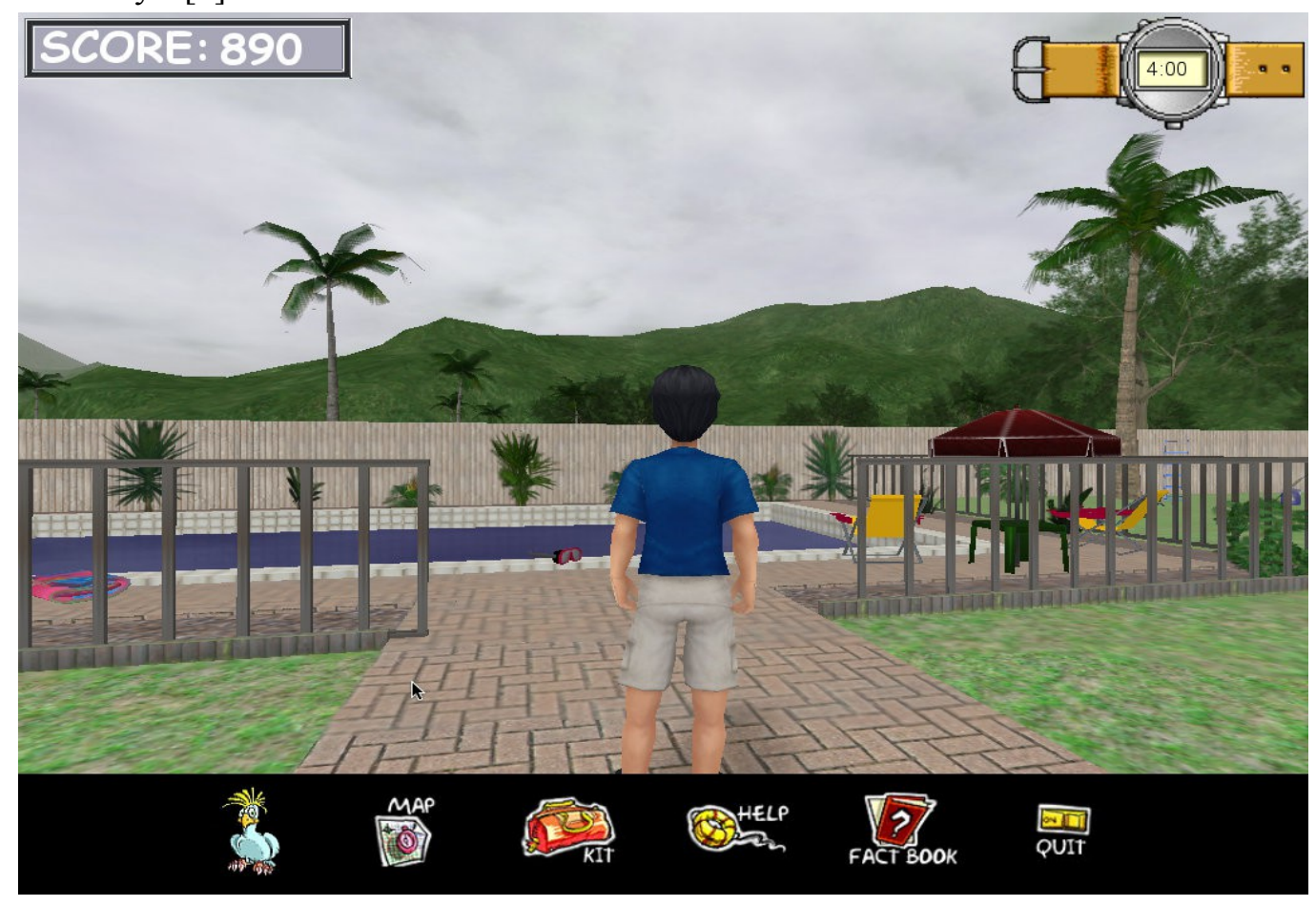

Figure 4: A screenshot of a scenario in 'Storm Watchers' [1]

\subsection{Earthquake School in the Cloud: Taiwan Experience}

Recently, cloud computing technology has been used in Taiwan to develop a near real-time earthquake games competion. The project leaders, K. Chen, W. Liang, and Y. Yu have these to say about their project:

"To better prepare the citizen for future impact of natural disasters, it is important to understand how previous disasters have occurred, why lives were lost, and what lessons have been learned. This will allow the attitude of society towards natural disasters to transform from training to learning. Taiwan may be the place on Earth most vulnerable to natural hazards, with $73 \%$ of its land and population exposed to greater than three natural hazards. Unlike flood, landslide, cyclone, and flood, earthquake takes only several to tens of seconds to react and respond. It is crucial therefore, to increase the citizen's capability and knowledge of earthquake science - why it happens, how it happens, and how do we prepare ourselves and city for earthquake hazard. 
In order to attract public involvement in inquiry and discovery of earthquake knowledge, citizen seismologists are highly encouraged. They are volunteers who can contribute on data collection, analysis, and reporting and have potential to greatly improve the emergency response to earthquakes. The citizen-seismologists-in-Taiwan project (CSTaiwan) is designed to elevate the quality of earthquake science education by means of incorporating earthquake/tsunami stories and educational earthquake games into the traditional curricula in schools. That is, it aims to build an earthquake school in the cloud computing service where teachers can easily teach about earthquakes and children can learn about earthquakes in a fun environment. Through a pilot program of courses and professional development workshops, we have worked closely with teachers in elementary, junior high, and senior high schools, to design workable teaching plans through a practical operation of seismic monitoring at homes and schools. With an update of the citizen seismic networks in Taiwan, in this paper we also demonstrate how 9-year-olds perform P-and S-wave picking and measure seismic intensity through an interactive learning platform, how scientists and school teachers work together, and how we create an environment to facilitate continuous learning (i.e., via a near-real time earthquake games competition) to make earthquake science fun." [5]

The mechanics of the game goes this way [5]:

When earthquake occurs, you can login to process the seismic data, to determine earthquake location (where this earthquake occurred), seismic intensity map (where the strongest shaking took place), and fault plane solution (is this earthquake a thrust, normal, or strike slip faulting?).

To become a "citizen seismologist", follow these steps"

A. Register as a citizen seismologist.

B. Get certificates at four games:

1. Finding earthquake

2. Measuring earthquake shaking

3. Sizing up earthquake

4. Measuring how fault moves 


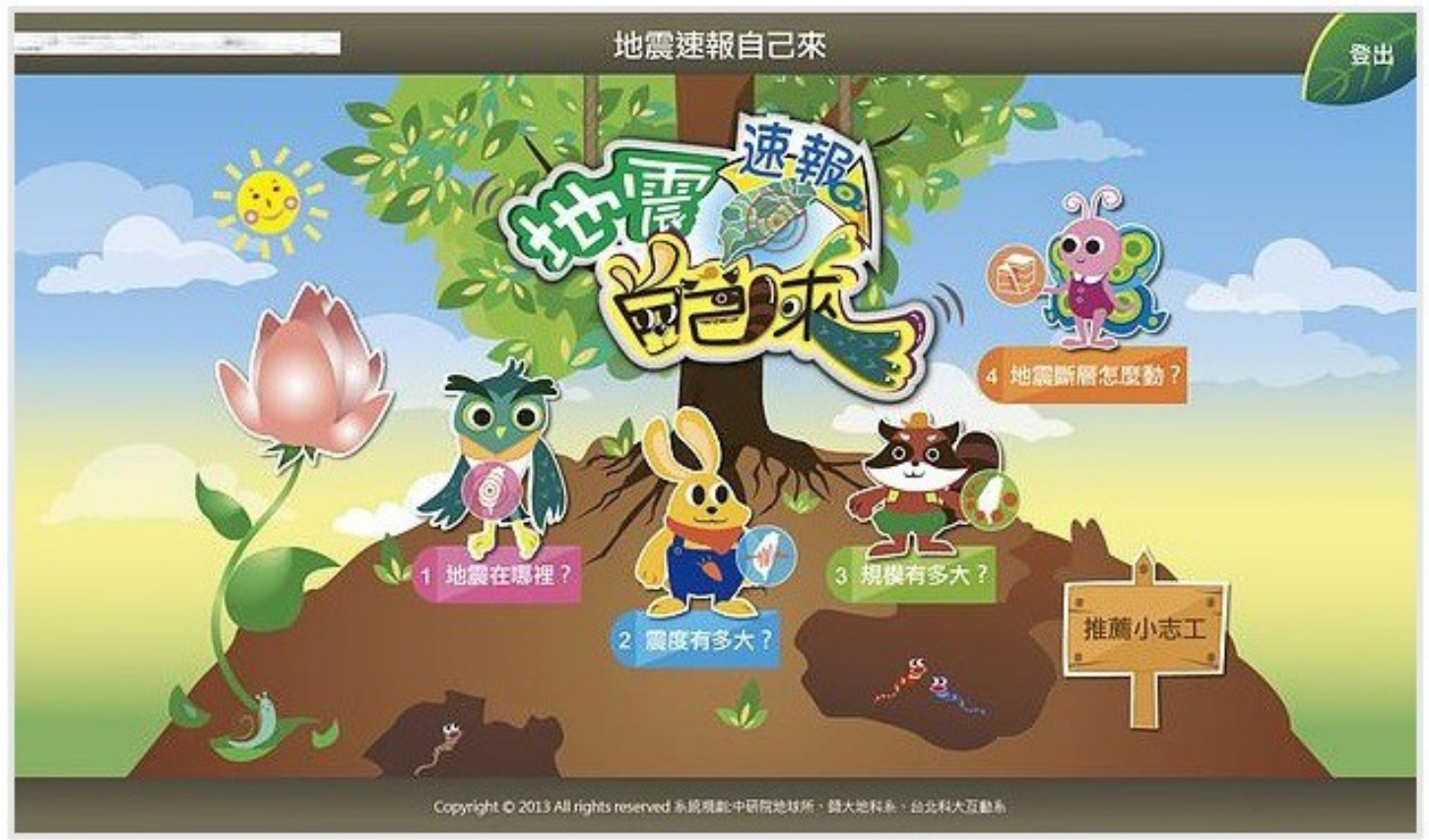

Figure 4: A screenshot of the website for Near Real-Time Earthquake Games in Taiwan [5]

\subsection{Integrating Computer Simulation Games in Disaster Preparedness and Risk Reduction Training: A Philippine Study}

The Philippines is one of the most hazard-prone countries in the world. This is due mainly to its geographic and geologic location and physical characteristics. The country is situated in the "Pacific Ring of Fire" , between two tectonic plates (Eurasian and Pacific), an area encircling the Pacific Ocean where frequent earthquakes and volcanic activity result from the movements of said tectonic plates. Recent statistics show that worldwide the Philippines has one of the highest number of people affected by natural disasters and has one of the highest disaster risk index. The country is exposed to a variety of hazards such as floods, earthquakes, typhoons, storm surges, tsunamis, volcanic eruptions, landslides, droughts and others.

In a study conducted by World Bank in 2008, the Philippines was identified as a natural hot-spot with approximately 50.3 percent of its total area and 81.3 percent of its population vulnerable to natural disasters. Also, according to the 2012 World Risk Report published by the United Nations University Institute of Environment and Human Security (UNU-EHS), the Philippines ranked as the third most disaster risk country worlwide with a Risk Index of 27.98 percent -- the highest in Asia [10].

In January 2005, one hundred sixty eight (168) governments met in Kobe, Japan to discuss how they could reduce the impact of disasters and adopted a plan of action. The plan is called the Hyogo Framework for Action 2005-2015: Building the Resilience of Nations and Communities to Disasters. It encourages governments, with support of United Nations (UN) agencies and civil societies to take preventive measures to reduce the risk of disasters at local, national, regional and global levels.

As a signatory to the Hyogo Framework for Action, the Philippines promulgated Republic Act 10121 (also known as the Philippine Disaster Risk Reduction and Management Act of 2010) which declares the following policies among others: "(a) Uphold the people's 
constitutional rights to life and property by addressing the root causes of vulnerabilities to disasters, strengthening the country's institutional capacity for disaster risk reduction and management, and building the resilience of local communities to disasters including climate change impacts;... (d) Adopt a disaster risk reduction approach that is holistic, comprehensive, integrated, and proactive in lessening the socioeconomic and environmental impacts of disasters including climate change, and promote the involvement and participation of all sectors and stakeholders concerned, at all levels, especially the local community."

To increase awareness on natural hazards in the Philippines and to promote disaster preparedness, risk reduction and management we conducted a study among young people in the country using computer simulation games developed by the United Nations/International Strategy for Disaster Risk Reduction. The subjects of this study are mainly teen-agers from public and private high schools, college level students from public and private universities, and young professionals. The study assessed the benefits of using computer simulation games in disaster risk reduction and the Filipino youth's perception on the disaster simulation game, "Stop Disasters!" $[7,8]$
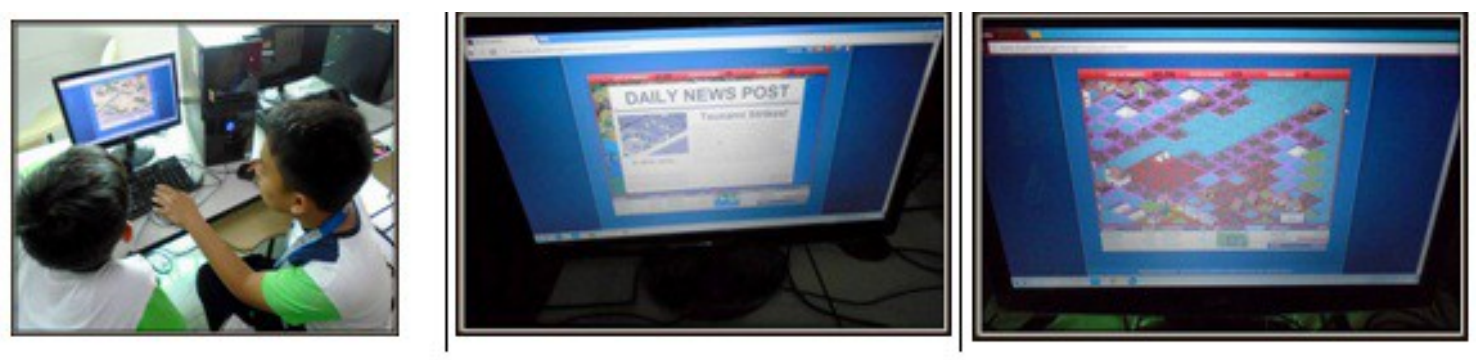

Figure 5: Snapshot of Grade 8 Filipino students [8]

After each game, the respondents were asked the following questions: (1) Do you think that computer simulation games can be beneficial in disaster preparedness, risk reduction and management? (2) What do like best in the game "Stop Disasters!"? (3) What don't you like in the game "Stop Disasters!"? (4) Would you recommend the game "Stop Disasters!" to your friends or relatives? Why or Why not? (5) Did the game "Stop Disasters!" increase your understanding of disaster preparedness, risk reduction and management? (6) Give suggestions/recommendations on how to improve the game "Stop Disasters!"

Ninety-eight percent ( $98 \%$ ) of repondents gave favorable responses to the question if computer simulation games can be beneficial in disaster preparedness, risk reduction and management.

Below are some sample explanations:

"It is most helpful to the teen-agers/children to know risk reduction awareness especially through visually interesting platforms such as computer simulation games."

"The game gives an idea on how proper management of resources can greatly prepare and protect a community against an incoming hazard/disaster." 
"It will give importance to capacity training and provision of social assistance to affected communities."

"The virtual experience gives us insight on disaster scenarios." "It gives people ideas on what to do in times of disasters."

Here are some recommendations:

1. Improve graphics.

2. More choices of icons, example, evacuation areas.

3. Improve selection of menus.

4. Improve user settings to allow better navigation.

5. Add more software options like livelihood projects, etc.

6. Add more hazard/disaster scenarios.

7. Add more features such as including problems occurring during disaster preparations.

8. Enhance social components/people activities.

9. Include real world scenarios/conditions so many people can relate.

10. Make offline versions.

11. Make mobile apps version (android/ios). Should be available on smart phone.

12. Include local languages/dialects (Tagalog, Cebuano, Waray, etc.).

13. Improve zooming in/zooming out capabilities and full screen viewing.

14. Include "community cooperation" aspect.

15. Increase budget allocation.

In summary, the study was able to ascertain the following:

1. There is overwhelming favorable responses to the use of computer simulation games such as "Stop Disasters!" in the education of the Filipino youth for disaster preparedness, risk reduction and management.

2. All respondents will recommend the game "Stop Disasters!" to be used by their friends/relatives.

3. Several recommendations were given to improve the game "Stop Disasters!" (technically, visually and content-wise) to suit it to local (Philippine) conditions/situation.

\subsection{Concluding Remarks}

In this paper, we presented a review of some computer simulation games pertaining to natural disasters. Among these games are as follows: "Stop Disasters!", "Disaster Master", "Storm Watchers", and Cloud-based Earthquake Simulation Games Competition.

Recommendations on how to improve the simulation game "Stop Disasters!" to suit local situations/conditions in the Philippines are given. 
With the "Earthquake School in the Cloud" project (that was developed in Taiwan) as a model, the next phase of this study is to integrate Cloud computing in an envisioned adaptation of "Stop Disasters!" simulation game for the Philippines.

\subsection{References}

[1] Bureau of Meteorology, Australian Government, Storm Watchers Game, available in http://www.bom.gov.au/storm watchers game/, last accessed on April 12, 2015.

[2] A. P. Craig, Interactive Preparedness Games, available in http://www.ehow.com/info 8303896 interactive-disaster-preparedness-games.html, last accessed on April 12, 2015.

[3] S.P.A.S. Felicio, A. R. Dargains, F. Sampaio, J.O. Gomes, V.S.R. Silva, P.R.A. Souza, P.V.R. Carvalho, and M.R.S. Borghes, Stop Disasters Game Experiment with Elementary School Students in Rio de Janairo: Building Safety Culture, in proceedings of the $11^{\text {th }}$ International ISCRAM Conference - University Park, Pennsylvania, USA, May 2014, S.R. Hiltz, M.S. Pfaff, L. Plotnick and P.C. Shih, eds.

[4] Disaster Master, available in http://www.ready.gov/kids/games/data/dmenglish/index.html, last accessed on April 12, 2015.

[5] Earthquake School in the Cloud: Citizen Seismologists in Taiwan (CSTaiwan),available in http://katepil6.wix.com/earthquake-school, last accessed on April 12, 2015.

[6] A. Garo, L. Nicoletti and F. Longo, Disasters Management: A Serious Game Architecture Centered on Modeling Simulation Infrastructure, in SCS M\&S Magazine. Vol. 4. Issue 1. ISSN 2168-703x.

[7] R. P. Saldaña, Integrating Computer Simulation Games in Disaster Preparedness, Risk Reduction and Management Education for Volunteers: Experiences in the Philippines. The Second Asian Conference on Society, Education and Technology (ACSET 2014), October 29 - November 2, 2014, Osaka, Japan.

[8] R. P. Saldaña, A Study on Raising Tsunami Awareness, Disaster Preparedness and Risk Reduction Among Young People in the Philippines Using Computer Simulation Games, The $7^{\text {th }}$ South China Sea Tsunami Workshop (SCSTW-7), November 18 - 22, 2014, Taichung, Taiwan.

[9] United Nations International Strategy for Disaster Risk Reduction (UN/ISDR), Stop Disasters!, available in http://www.stopdisastersgame.org, last accessed on April 12, 2015.

[10] United Nations University Institute of Environment and Human Security (UNU-EHS), World Risk Report 2012, available in https://www.ehs.unu.edu/file/get/10487.pdf, last accessed on April 12, 2015. 